January 1992

\title{
Psychiatric Interventions with Burned Children
}

Ravi Bhalla, M.D.

Bergen Pines County Hospital, Paramus, New Jersey

Diane Kaufman, M.D.

Bergen Pines County Hospital, Paramus, New Jersey

Diane Schrier, M.D.

Bergen Pines County Hospital, Paramus, New Jersey

Follow this and additional works at: https://jdc.jefferson.edu/jeffjpsychiatry

Part of the Psychiatry Commons

Let us know how access to this document benefits you

\section{Recommended Citation}

Bhalla, M.D., Ravi; Kaufman, M.D., Diane; and Schrier, M.D., Diane (1992) "Psychiatric Interventions with Burned Children," Jefferson Journal of Psychiatry. Vol. 10 : Iss. 1 , Article 7.

DOI: https://doi.org/10.29046/JJP.010.1.004

Available at: https://jdc.jefferson.edu/jeffjpsychiatry/vol10/iss1/7

This Article is brought to you for free and open access by the Jefferson Digital Commons. The Jefferson Digital Commons is a service of Thomas Jefferson University's Center for Teaching and Learning (CTL). The Commons is a showcase for Jefferson books and journals, peer-reviewed scholarly publications, unique historical collections from the University archives, and teaching tools. The Jefferson Digital Commons allows researchers and interested readers anywhere in the world to learn about and keep up to date with Jefferson scholarship. This article has been accepted for inclusion in Jefferson Journal of Psychiatry by an authorized administrator of the Jefferson Digital Commons. For more information, please contact: JeffersonDigitalCommons@jefferson.edu. 


\title{
Psychiatric Interventions with Burned Children
}

\author{
Ravi Bhalla, M.D.
}

\begin{abstract}
This paper reviews the literature and identifies etiologic and management factors in the care of the burned child. It was provoked by direct involvement with two sisters, seriously burned under similar circumstances, each at age two. Their suffering is shared by approximately 500,000 children each year. Despite the enormity of the problem, psychological evaluation and treatment interventions are still not routinely incorporated into the care of these children and their caregivers. The authors hope to encourage psychiatrists and other mental health professionals to become more involved in the prevention, diagnosis, treatment, and clinical investigation of the burned child.
\end{abstract}

\section{INTRODUCTION}

Twenty years ago, a paper, "The Burned Child-A Neglected Area of Psychiatry" (1), was presented at the 123rd Annual Meeting of the American Psychiatric Association. The neglect highlighted in that paper persists. Burns cause more pain, disability, and disfigurement, than perhaps any other childhood injury or illness. Ravenscroft (2) has documented repeated reports in the literature about the high psychological morbidity associated with burns. Despite this, primary care physicians and mental health professionals still do not routinely emphasize the evaluation and treatment of psychological traumas associated with burns. The authors hope that the current paper will encourage psychiatrists and other mental health professionals to become more aware of the psychological issues surrounding burns in children. The following case of two sisters, who were seriously burned as toddlers, inspired us to review etiological and management factors in the care of the burned child, and led us to the conclusion that much work still needs to be done in this area.

\section{Case Report 1}

A \& B, two sisters ages 2 and 4, were referred to the outpatient child psychiatry clinic by a child protective agency. Child A had been treated at a local burn unit at 22 months following second degree burns over $20 \%$ of her body, caused by scalding. The nature of the burns raised suspicions that they were caused by direct abuse. Child $\mathrm{A}$ was observed by staff nurses to be withdrawn and emotionally unresponsive, not even crying during the changes of her dressings. The burn unit staff recommended a 
psychiatric evaluation, and she was referred to the preschool outpatient psychiatric service.

\section{Case Report 2}

Child B, the older sister, had been similarly burned when she was 2 years old. She had never been referred for psychiatric evaluation or treatment. The local child protective agency had investigated her injuries, but found insufficient grounds to compel either legal or psychiatric intervention. Child B had been scalded while being given a bath by her mother's boyfriend, who was the father of her younger sister. Child A reportedly received a scalding burn while the mother's best friend was baby-sitting her. The mother stated that most probably her friend immersed Child A in hot water to "discipline" her for soiling herself, even though "she is toilet trained." After the second incident, both children were removed and placed in separate foster homes.

At the time of our evaluation, Child B exhibited undue familiarity with strangers; with her history of physical abuse she met DSM-III-R Criteria for reactive attachment disorder. Child A showed evidence of major depression by DSM-III-R Criteria due to symptoms of severely constricted affect, lack of interest, difficulty in falling asleep, decreased appetite, loss of language skills and bed-wetting at night. Neither child fulfilled DSM-III-R criteria of post traumatic stress disorder (PTSD), despite symptoms suggestive of this disorder. Child A did not show evidence of persistently reexperiencing the trauma and could not "put trauma to words" as noted by Terr (3). Child B was able to verbalize some aspects of trauma through "repetitive, monotonous play" (4). She did not show any evidence of "increased arousal" and "persistent avoidance of stimuli associated with trauma or numbing of general responsiveness" described in DSM-III-R. This illustrates that a child's developmental phase is very relevent in screening for PTSD $(5,6)$. The children's mother did not show any anger toward the individuals responsible for her children's burns, and remained friendly with them. The mother described her own mother as being very cold and unavailable as well as physically abusive.

At the completion of the evaluation, both children were enrolled in play therapy to encourage working through their traumatic experiences. The mother was referred for individual psychotherapy in the adult outpatient clinic so that she might better appreciate her children's trauma, and learn more effective parenting skills. Five months later, both sisters showed significant symptomatic improvement. Child A was moved to the same foster home where her older sister was living, a move which was strongly recommended to the child protection agency by the treatment program.

Discussion with the medical director of the Burn Unit where these children had been treated revealed that assessment by a child psychiatrist or other mental health professional was not routine, and referral occurred only if the child showed some striking features of an emotional disorder. The Burn Unit had only a part-time psychiatric nurse-clinician to do evaluations and consultations for a limited number 
of patients. The child protective agency also did not routinely require mental health evaluations and interventions in cases of burns in children.

\section{EPIDEMIOLOGICAL CONSIDERATIONS}

According to information obtained from the National Burn Victim Foundation (22 Main Street, Orange, N.J., unpublished data, 1989) approximately 500,000 children suffer significant burn injuries every year. Out of these, 100,000 have serious burns (e.g., 2nd degree burns of at least 15\% of total body surface, and any 3rd degree burns) requiring hospitalization. Hight (7) studied 872 children admitted to a burn center and found that $16 \%$ had burn injuries inflicted by others. The average age of children so abused was 32 months, and the male to female ratio was approximately 2 to 1 .

Purdue and Prescott (8) emphasized the need for physicians to be alert to inflicted burns as an often unrecognized form of child abuse. They reviewed 66 children with inflicted burns over a four and a half year period, and found that the mean age was $2.2 \pm 0.3$ years ( $73 \%$ less than 2 years old). They found that the mean burn size was $12.9 \% \pm 1.4 \%$. Scalds were found to be the most frequent $(80 \%)$ cause of inflicted burns. Campbell (9) suggested that the occurence of both accidental and intentional burn injuries was social-class related. After studying 286 patients admitted to the pediatric burn unit at Riley Children Hospital during the period from 1977 to 1982 , they found that most of their patients $(84.9 \%)$ were from families in social class 5 of the Hollingshead classification. Thus, most of these children belong to families with lower socio-economic status. Inflicted burns were diagnosed in approximately $10-20 \%$ of these children. Most of the children with inflicted burn injuries were approximately 2 years old, and boys were inflicted with burn injuries twice as commonly as girls.

\section{ETIOLOGICAL CONSIDERATIONS}

Martin (10) described four patterns of conflict which antedated 41 separate accidents leading to burns in 45 children. These patterns were: 1) internal struggle of the mother, e.g., emotional preoccupation with pregnancy, illness, or unemployment; 2) conflict between parent and child for control; 3) conflict between siblings; 4) conflict between hostile parents or adults. These patterns emerged from a careful history of the incident and its surrounding circumstances. The author suggests, "Injury to children denotes a breakdown in the protection of the child either by the parents when he is too young to care for himself, or by the child when he is mature enough to have acquired the capacity for self-preservation..." She attributes this breakdown to the emergence of destructive feelings within a family constellation, but which maintains sufficient integrity to deter overt acts of abuse.

Seligman (1) found that out of 23 families interviewed, 14 had a history of early parental loss suffered by the parents of the accidental burn victims. In one case the child suffered a serious accidental burn at the same age that her mother had been 
the return to home and to school, including facing the reaction of the world to his or her disfigurement.

\section{LONG TERM SEQUELAE AND MANAGEMENT}

Stoddard (13) did a follow-up study of 30 children more than 6 months after severe burns and found that burned children had significantly higher levels of over-anxious disorder, phobia, and enuresis. However, they had the same rate of depressive disorder as a control group. Their sample size was small; more multicenter studies with larger numbers are needed before these findings can be conclusive. Bernstein (14) found that most surgeons have lost contact with all but a small group of patients. Long term follow-up by a mental health professional is even less common.

Stoddard (11) and Bernstein (13) have discussed body image problems in burn victims. In our case example, Child B told the therapist one day during a therapy session: "My burns (scars) are going to be washed away and then I will live with my mommy," and then put water on her scars to demonstrate. Only long term case studies will reveal how children process their understanding of traumatic events and how they adapt their body image to its trauma-induced changes. Bowden (15) studied self esteem and general social adjustment in 320 persons, 10 years and older, treated at the Burn Center, University of Michigan. She found that children who were burned at ages up to 11 years had the lowest self esteem, suggesting that children may be less able to cope effectively with the psychic trauma of serious burn.

\section{DISCUSSION}

Much has been learned about the psychiatric management of burned children in the last few years, particularly in medical inpatient settings. Some, but not all, major burn units have a team comprised of a child psychiatrist, a psychologist, social worker and a psychiatric nurse clinician. Many burn units still operate with minimal psychiatric input. Even though there are significant long term psychiatric sequelae, and attendant social costs, there is very little outpatient follow-up. As with many needed psychiatric services in medical settings, economics, including insurance reimbursement, dictate what services are made available. Denial of the psychological trauma is not limited to patients and families, but is often shared by physicians and mental health workers. It is very stressful working with burn victims.

New research efforts are needed to clarify the psychological needs of burned children and their families. This particularly applies to the long-term consequences of burns, in which disfigurement represents an ongoing trauma which must be processed by the patient and the family. Such clarifications of the burn victim's needs would surely buttress more self-evident justifications for allocating necessary funds for the burn victims' psychological care, as well as increase awareness about psychological trauma associated with burns. 
Finally, we wish to emphasize that every burn victim warrants a thorough psychiatric evaluation and management plan, not only immediately after his or her injury, but for as long as is necessary.

\section{REFERENCES}

1. Seligman R, MacMillon B, Carroll S: The burned child: A neglected area of psychiatry. Am J Psychiatry 128:52-57, 1971

2. Ravenscroft K: The burn unit. Psychiatric Clin. of N. America 5:419-432, 1982

3. Terr L: What happens to the early memories of trauma? A study of twenty children under five at the time of documented traumatic events. Am J Child Adolesc Psychiatry 27:96-104, 1988

4. Terr L: Forbidden games-post traumatic child's play. J Am Acad Child Psychiatry 20:741-760, 1981

5. Lewis M: Child and adolescent psychiatry a comprehensive textbook, Baltimore, Williams \& Wilkins, 1991

6. Terr L: Too scared to cry, New York, Harper \& Row, 1989

7. Hight $\mathrm{D}$, Babalar $\mathrm{H}$, Lloyd $\mathrm{J}$ : Inflicted burns in children-recognition and treatment. JAMA 242:517-520, 1979

8. Purdue GF, Hunt JL, Prescott PR: Child abuse by burning - an index of suspicion. Proc of the Am Burn Assoc Nineteenth Annual Meeting Washington, D.C. 1977; p. 171

9. Campbell J, LaClave L: Clinical depression in pediatric burn patients. Burns 13:213-217, 1987

10. Martin H: Antecedents of burns and scalds in children. Br J Med Psychol 43:39-47, 1970

11. Stoddard F: Coping with pain-a developmental approach to treatment of burned children. Am J Psychiatry 139:736-740, 1982

12. Bernstein N, Sanger S, Fras I: The functions of the child psychiatrist in the management of severely burned children. J Am Acad Child Psych 8:620-63512, 1969

13. Stoddard ND, Murphy JM, Beardslee W: Psychiatric outcome of burned children and adolescents. J Am Acad Child Adolesc Psychiatry 4:589-595, 1989

14. Bernstein N: Emotional problems of facially burned and disfigured children. Boston, Little Brown Co, 1976

15. Bowden ML, Feller I, Davidson T: Self esteem of severly burned patients. Arch. Phys. Med Rehabil 61:449-452, 1981 